\title{
Loop - Tabuleiro Lógico: uma proposta de ensino com Computação Desplugada
}

\author{
Ruan Soares Barroso', Ana Rita de Souza dos Santos², \\ Veruska Ribeiro Machado ${ }^{3}$ \\ ${ }^{1}$ Instituto Federal de Brasília - Campus Taguatinga \\ ${ }^{2}$ Instituto Federal de Brasília - Campus São Sebastião \\ ${ }^{3}$ Instituto Federal de Brasília - Campus Taguatinga \\ ruansoares284@gmail.com, vr.anarita@gmail.com, \\ veruska.machado@ifb.edu.br
}

Resumo: Loop: tabuleiro lógico foi pensado como uma proposta de ensino gamificado que pudesse inserir as crianças no mundo da computação e da programação de uma forma interdisciplinar e inovadora. Trabalha-se com os principais conceitos do pensamento computacional a partir da transposição didática de conteúdos e ressignificação de conceitos complexos.

Abstract: Loop: logic board was thought of as a proposal of teaching that could introduce children into the world of computing and programming in an interdisciplinary and playful way. We work with the main concepts of computational thinking from the didactic transposition of contents and re-signification of complex concepts.

\section{Introdução}

As sociedades do século XXI estão inseridas em um mundo em constante transformação e, para uma adaptação bem-sucedida a esse mundo, são necessários novos conhecimentos e habilidades.

Nesse contexto, o ensino de conceitos de programação e do pensamento computacional fornecerá uma nova visão, assim como novas possibilidades de raciocínio, diante de problemáticas diárias. O objetivo não é tornar o aprendiz um programador ou um cientista da computação, mas sim desenvolver habilidades requeridas em um mundo imerso em tecnologias digitais.

Para o desenvolvimento dessas habilidades, é possível adotar uma perspectiva interdisciplinar, que pode ser entendida como uma proposta de prática pedagógica que 
propicia a interação dos saberes a fim de consolidar, assegurar, capacitar e contextualizar o processo de aprendizagem dos discentes. Há que se destacar que a Computação demonstra uma grande capacidade interdisciplinar, contribuindo, desde a sua origem, com o desenvolvimento de vários métodos e soluções de problemas nas mais diversas áreas.

Neste trabalho, parte-se da perspectiva da interdisciplinaridade envolvendo três áreas de conhecimento: computação, matemática e língua portuguesa. O objetivo foi desenvolver um recurso pedagógico para o ensino de conteúdos da computação explorando a interdisciplinaridade com matemática e língua portuguesa. $\mathrm{O}$ recurso elaborado foi um jogo e a proposta é de que seja utilizado em aulas desenvolvidas com base em metodologias ativas.

O jogo, denominado Loop - Tabuleiro Lógico, não exige conhecimento prévio em computação para participar, pois se pode aprender enquanto joga, ou seja, de forma prática, aprende-se fazendo.

Para a elaboração do jogo, considerou-se, ainda, que as habilidades relacionadas ao pensamento computacional podem ser exploradas de forma 'plugada', isto é, utilizando o computador, ou de forma 'desplugada', por meio da técnica da Computação Desplugada, que foi a utilizada neste trabalho.

A computação desplugada é uma técnica que visa ensinar os fundamentos da computação de forma ativa e sem o uso de computadores (BELL et al. 2011). De acordo com (VIEIRA et al. 2013), essa técnica pode ser aplicada para indivíduos de todas as idades, desde o ensino básico até o ensino superior, com diferentes experiências e capacidades. Sendo assim, o Loop: Tabuleiro Lógico é uma proposta desplugada e interdisciplinar para o ensino da computação.

Este artigo apresenta, assim, resultados preliminares da experiência com o Loop, em que o trabalho desenvolvido tem sido norteado pelos seguintes objetivos: utilizar a computação desplugada para desenvolver o raciocínio lógico dos participantes, promover a transposição didática de conteúdos computacionais, explorar a interdisciplinaridade no ensino de conteúdos da computação e estimular a resolução de problemas.

Além desta introdução, este artigo está organizado em outras três seções. A seção dois descreve como o projeto foi realizado, bem como o planejamento e elaboração do jogo. Na terceira seção serão descritos e discutidos os resultados obtidos. Por fim, as considerações finais são apresentadas na quarta e última seção.

\section{Percurso metodológico}

O objetivo do trabalho foi desenvolver um recurso pedagógico para o ensino de conteúdos da computação explorando a interdisciplinaridade com matemática e língua portuguesa. Assim, foi criado o jogo Loop - Tabuleiro Lógico para ser utilizado como recurso em aulas que desenvolvem metodologias ativas no processo 
ensino-aprendizagem. O jogo consiste em apresentar os conteúdos utilizando os princípios da técnica de computação desplugada, de uma forma interdisciplinar e lúdica.

A elaboração do jogo contou com as seguintes etapas: i) seleção dos conteúdos a serem explorados no Loop; ii) definição da técnica a ser utilizada no jogo; iii) construção de um protótipo; iv) aplicação do protótipo; v) avaliação e revisão do protótipo.

A seleção dos conteúdos ocorreu da seguinte forma: foi feito um levantamento dos objetos de conhecimento e das habilidades apontadas nos currículos de referência para o ensino da computação sugeridos pela Sociedade Brasileira de Computação (SBC). Feito esse levantamento, estabeleceu-se relação entre esses objetos do conhecimento e os objetos de conhecimentos relacionados à matemática e língua portuguesa. Assim, chegou-se à seleção final.

$\mathrm{Na}$ segunda etapa, após o estudo das possibilidades do jogo plugado e desplugado, optou-se pelo desplugado, principalmente por permitir a utilização em contextos educacionais com parcos recursos tecnológicos.

A construção do protótipo levou em conta princípios da técnica "computação desplugada", como: não requerer o uso de computadores; aprender fazendo; ser divertido; não utilizar nenhum equipamento especializado; destacar a solução de problemas durante as atividades; as atividades podem ser usadas independentemente umas das outras; atividades flexíveis com relação a erros, isto é, pequenos erros não impedem que os(as) participantes entendam os fundamentos.

Finalizado o protótipo, partiu-se para a sua aplicação, que ocorreu em cinco eventos distintos, cuja descrição encontra-se no item 2.2 deste texto. Ao final das aplicações, entrevistas foram realizadas com as pessoas que participaram das oficinas com o intuito de verificar se, de fato, os objetivos do jogo estavam sendo atingidos utilizar a computação desplugada para desenvolver o raciocínio lógico dos participantes, promover a transposição didática de conteúdos computacionais, explorar a interdisciplinaridade no ensino de conteúdos da computação e estimular a resolução de problemas. Na oportunidade, os(as) participantes puderam destacar os pontos positivos e negativos do tabuleiro. A seguir, encontra-se, no item 2.1, a descrição do jogo e, no item 2.2, descrição dos contextos de aplicação do jogo.

\subsection{O Jogo}

Utilizou-se um jogo de tabuleiro para desenvolver alguns dos principais conceitos computacionais. $\mathrm{O}$ formato do tabuleiro do jogo se diferencia por ser redondo, conforme pode ser visto na Figura 1. 
VIII Congresso Brasileiro de Informática na Educação (CBIE 2019)

Anais do XXV Workshop de Informática na Escola (WIE 2019)

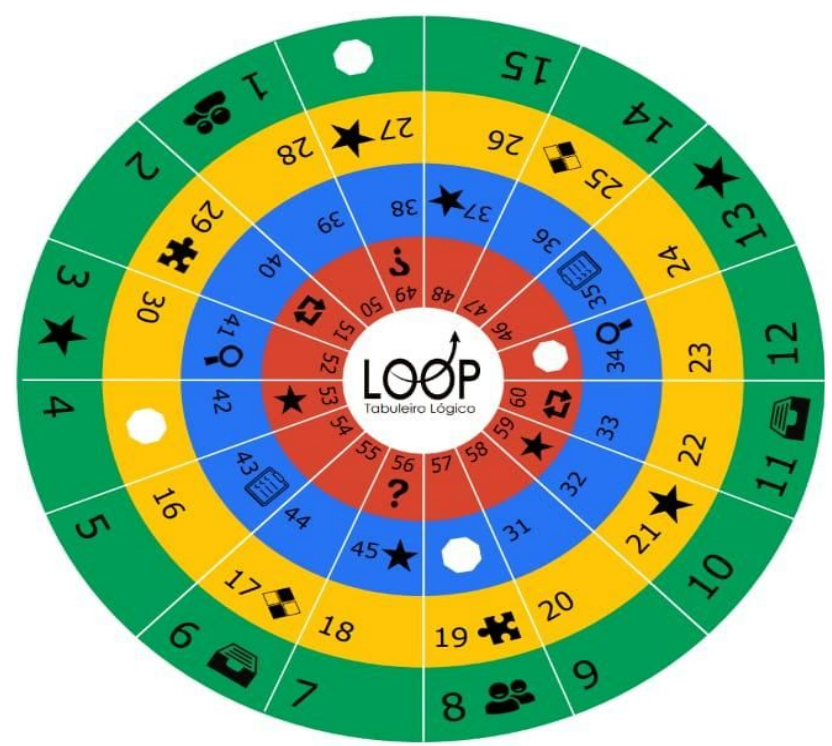

Figura 1 - Tabuleiro Loop

Podem jogar de dois a seis participantes por tabuleiro, a partir de oito anos de idade. O jogo possui quatro níveis de dificuldades (verde, amarelo, azul e vermelho) cada um com dois desafios distintos. Cada jogador(a) tem três vidas, sendo que perde uma vida o(a) jogador(a) que perder um desafio. Se o(a) participante perder as três vidas no Nível Verde, ficará uma rodada sem jogar. Mas, se perder as vidas no Nível Amarelo, Azul ou Vermelho, volta para o nível anterior. O objetivo do(a) jogador(a) é ser o(a) primeiro(a) chegar ao centro do jogo. Contudo, para isso, o(a) jogador(a) só poderá subir para o próximo nível se cair na casa que tem um octógono.
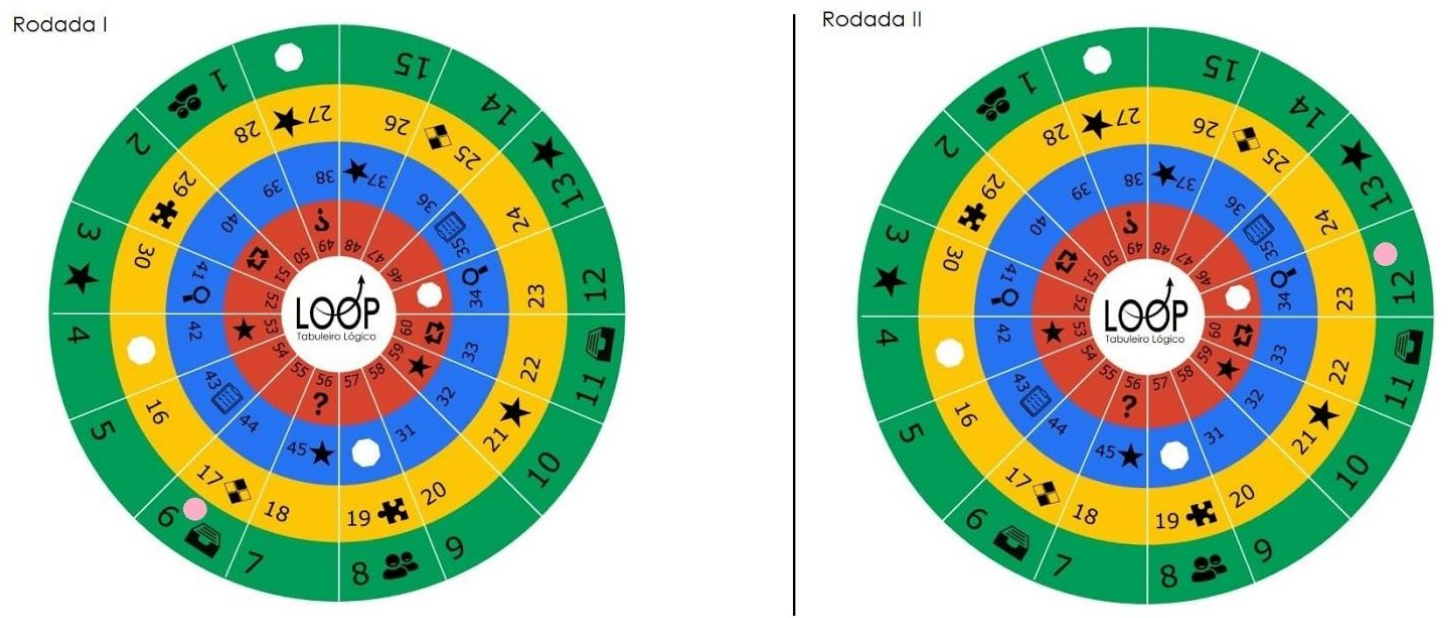

Figura 2 - Exemplo de Jogada no Nível Verde

$\mathrm{Na}$ Figura 2, o jogador tirou o número seis no dado na rodada 1 e tirou novamente seis na rodada seguinte. Assim, para subir para o próximo nível, o jogador deverá tirar o número quatro no dado, pois precisará cair exatamente no octógono. Mas, se o jogador tirar, por exemplo, o número cinco ou seis ele ficará em um loop. Assim, só é possível sair deste laço de repetição de duas formas: cair no octógono ou após ter dado duas voltas completas no nível correspondente (tendo em vista que o jogador 
poderia ficar em um loop infinito, essa regra foi criada para não deixar o jogo exaustivo).

Como já mencionado, o jogo possui dois desafios distintos em cada nível, sendo esses os seguintes:

\section{Usuário (Nível Verde)}

É apresentada a sombra de uma personagem e o(a) jogador(a) deve dizer qual o seu nome e definir duas variáveis quantitativas e duas variáveis qualitativas.

\section{Identifique (Nível Verde)}

$\mathrm{O}(\mathrm{A})$ jogador(a) deverá ler, interpretar e responder o desafio baseado nas dicas correspondentes. Assim, será possível determinar o nome das personagens e suas respectivas informações.

\section{Padrão Lógico (Nível Amarelo)}

Um problema envolvendo padrões é apresentado para o(a) jogador(a) que deve dizer qual o próximo número e/ou letra da sequência. Além de definir o tipo de dado correspondente, ou seja, se é um inteiro, real ou texto.

\section{Puzzle Binário (Nível Amarelo)}

É dada uma tabela em decimal ou binário, sendo que o(a) jogador(a) deve converter para a outra base e colocar os números convertidos na posição correspondente.

\section{Ordem (Nível Azul)}

$\mathrm{O}$ (A) jogador(a) observa um problema envolvendo variáveis e então deverá definir o valor das variáveis de acordo com a ordem que aparecem e resolver a operação matemática.

\section{Detetive (Nível Azul)}

É apresentada uma palavra criptografada para o(a) jogador(a), sendo que o(a) mesmo(a) deve descriptografar com o auxílio da cifra de césar para que descubra a palavra escondida.

\section{Fluxo Lógico (Nível Vermelho)}

Um problema lógico é apresentado para o(a) jogador(a), que deverá solucioná-lo através de um fluxograma. Por conseguinte, será preciso, antes de tudo, fazer um algoritmo.

\section{Enigma (Nível Vermelho)}

$\mathrm{O}(\mathrm{A})$ jogador(a) deve ler um texto e definir um perfil ou relatório com todas as informações coletadas. Contudo, para isso, deverá atribuir valores lógicos às afirmações, isto é, 0 (zero) se a afirmação for falsa e 1 (um) se a afirmação for verdadeira. 
VIII Congresso Brasileiro de Informática na Educação (CBIE 2019)

Anais do XXV Workshop de Informática na Escola (WIE 2019)

Vale ressaltar que existem ainda casas com estrelas. Quando o(a) jogador(a) cair nesta casa, deverá comprar um card. Estes cards podem dar uma vantagem ou desvantagem para o(a) participante como: subir para o próximo nível, ficar uma rodada sem jogar, voltar ao nível 1, ganhar uma vida extra etc.

\subsection{Aplicação do Loop}

Cada partida do jogo durou, em média, de 30 a 90 minutos, sendo que os desafios baseiam-se em conteúdos do pensamento computacional: algoritmos, estruturas de decisão e repetição, fluxogramas, variáveis (quantitativas e qualitativas), detecção de erros, criptografia, números binários, tipos de dados e valores lógicos. Além disto, apresenta desafios baseados em conceitos de matemática e de português através, respectivamente, de problemas envolvendo padrões e ordenamento e leitura e interpretação de textos.

O jogo foi aplicado em cinco eventos distintos, sendo estes: Campus Party Brasil 2019 (CPBR12), Festival Latino Americano de Instalação de Software Livre 2019 (FLISOL), V Semana de Ciência, Cultura e Arte do Instituto Federal de Brasília (IFB) Campus São Sebastião (2019), Campus Party Brasília 2019 (CPBSB3) e LabKids Festival (IFB) 2019 nesta ordem. Ao todo, mais de cem participantes puderam aprender mais sobre os fundamentos da computação. Contudo, cada aplicação contou com um público-alvo diferente e/ou uma versão diferente do jogo. Na figura 3 pode ser vista uma das aplicações do jogo.

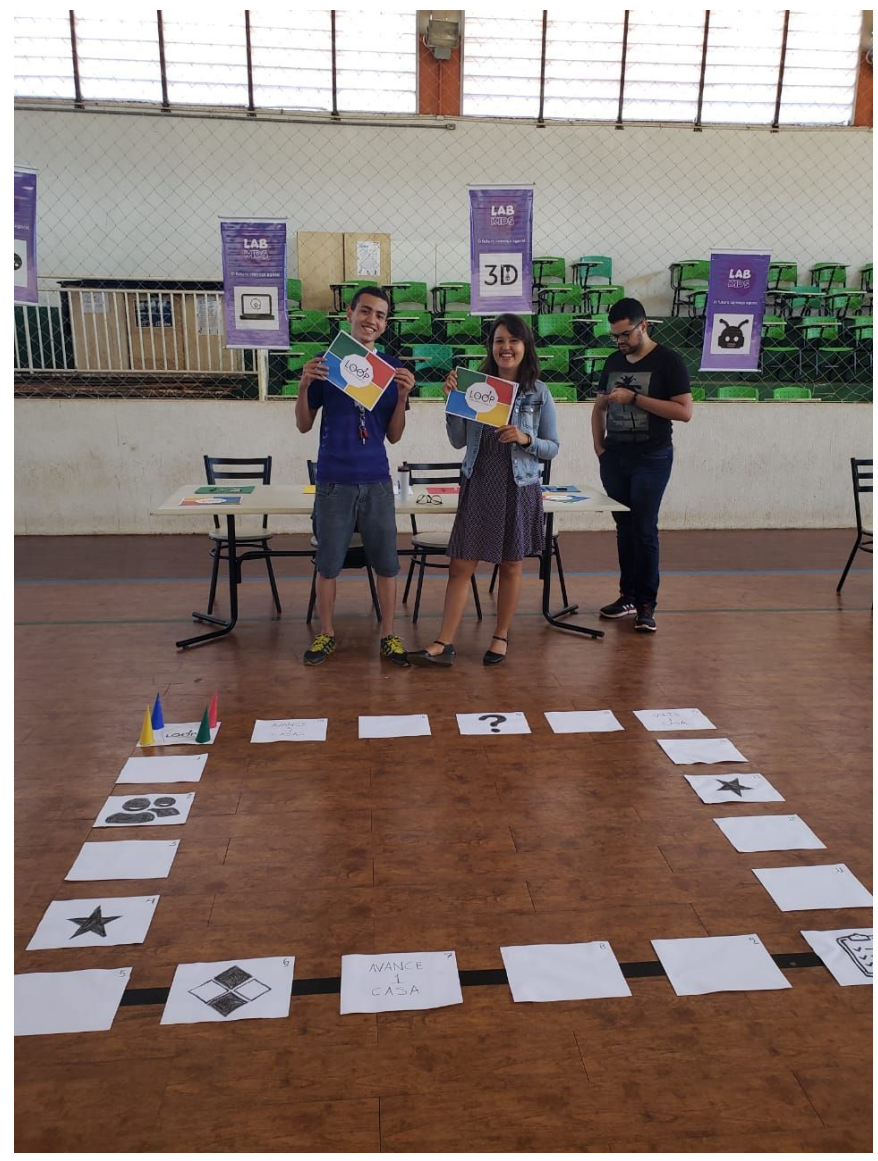


VIII Congresso Brasileiro de Informática na Educação (CBIE 2019)

Anais do XXV Workshop de Informática na Escola (WIE 2019)

\section{Figura 3 - Aplicação do Loop: Tabuleiro Lógico}

A primeira versão foi criada para jovens e adultos a partir de 16 anos, sendo aplicado na CPBR12. Em seguida, o jogo foi aprimorado e alguns desafios foram modificados para que, assim, houvesse uma versão para crianças e adolescentes a partir de 8 anos de idade. Por conseguinte, esta versão foi aplicada em três eventos: no FLISOL, na V Semana de Ciência, Cultura e Arte do IFB - CSS e na Campus Party Brasília 2019. Contudo, em cada evento, contou-se com um público diverso. No FLISOL, participaram crianças e adolescentes. Já no Campus São Sebastião/IFB, houve a participação de crianças, adolescentes e adultos com idade superior a 30 anos. Na CPBSB3, crianças puderam jogar com seus responsáveis. Por fim, no LabKids Festival 2019, o Loop foi jogado apenas com crianças, porém a aplicação do jogo foi em um tabuleiro de chão, sendo que os desafios não sofreram alteração, apenas o formato do tabuleiro.

\section{Resultados e Discussão}

Observou-se, através da aplicação do Loop, a possibilidade de apreender os conceitos iniciais de computação tendo em vista que trabalha, principalmente, a lógica. Estudar lógica proporciona as pessoas analisarem e identificarem processos incorretos de raciocínio, tanto das outras pessoas quanto os seus próprios. Através dos desafios, podemos ver qual o método de raciocínio utilizado pelos participantes, bem como os erros e acertos. Em outras palavras, ver se as respostas têm sentido, consequentemente, trazendo à tona a lógica de programação.

Sabe-se que existem etapas importantes para desenvolver um programa, entre elas está a lógica de programação. As habilidades relacionadas à lógica de programação, conforme apontado na introdução, são indispensáveis na contemporaneidade, pois no cotidiano é preciso lidar com problemas complexos, que exigem concentração e razão lógica. Um erro pode gerar muitas consequências. Por conseguinte, o tabuleiro traz desafios que aumentam a capacidade dos jogadores para solucionar e identificar problemas.

Em cada aplicação do Loop, trabalhou-se com um público diferente e, consequentemente, obteve-se resultados distintos. Na primeira aplicação, feita para jovens e adultos, os(as) participantes já tinham um conhecimento prévio em grande parte dos conteúdos de programação. Porém, tiveram dificuldades com os desafios que envolviam conteúdos matemáticos e de português. A seguir constam alguns desafios enfrentados nas aplicações.

Em um dos desafios, havia o seguinte problema: Defina o próximo número e/ou letra da sequência: $\mathbf{2}, \mathbf{3}, \mathbf{5}, \mathbf{7}, \mathbf{1 1}, \mathbf{1 3}, \mathbf{1 7}, \ldots$. A resposta do problema era 19 , pois a sequência se trata dos números primos. Mas, um dos participantes que pegou este desafio, não soube responder e acabou perdendo uma das vidas que tinha no jogo. Ao final da partida, o mesmo jogador pediu a resolução do problema e, quando percebeu que se tratava dos números primos, ficou surpreso, pois já havia estudado este conteúdo, mas não se recordava. Sobre o fato, ele comentou: "São coisas simples que já 
VIII Congresso Brasileiro de Informática na Educação (CBIE 2019)

Anais do XXV Workshop de Informática na Escola (WIE 2019)

aprendemos, mas que não vemos há um tempo e acabamos esquecendo.". Além disso, os(as) participantes sugeriram uma mudança no jogo para que não fosse necessário que o(a) próximo(a) jogador(a) esperasse terminar o desafio para jogar, ou seja, enquanto o(a) jogador(a) resolvia o desafio, os demais continuavam jogando até o(a) jogador(a) terminar o problema.

Para a segunda aplicação, no FLISOL, foram modificados alguns desafios, tendo em vista que o público, agora, era de crianças e adolescentes, que não tinham conhecimento algum em computação. Apesar de não conhecerem os conteúdos, todos aprenderam na medida em que foram jogando. Alguns tiveram dificuldades em desafios que envolviam interpretação de texto, porém, apesar de errarem alguns desses desafios, não deixaram de aprender os fundamentos computacionais. Ao término da partida, os(as) participantes queriam jogar uma segunda vez, pois não chegaram a passar do nível azul.

A terceira aplicação contou com vencedores nas partidas, diferente das duas aplicações anteriores, nas quais nenhum participante chegou ao centro do jogo. Além do mais, a terceira aplicação se destaca por contar com três públicos diferentes, sendo de crianças, adolescentes e adultos com idade superior a trinta anos de idade. Muitos tiveram dificuldade com desafios envolvendo interpretação de texto, além de que alguns 'sacrificavam' uma das três vidas do jogo para não realizar o desafio. Os principais motivos para não ser preciso fazer o desafio foram: a influência dos oponentes ao dizer que o desafio era difícil e referências culturais envolvidas no jogo. Em um dos desafios, era preciso definir o nome da personagem, bem como suas características, mas grande parte dos adultos não conheciam as personagens, pois estas não fazem parte das suas referências culturais. Apesar disso, boa parte dos desafios foi realizada. Um aluno do $1^{\circ}$ ano do ensino médio disse: "Não era difícil, só um pouco trabalhoso... deveria ter mais níveis e com mais dificuldades. ”. Daí, surge a possibilidade da criação de novas versões do tabuleiro com diversos níveis de dificuldade e adaptados de acordo com a idade por causa das referências culturais nele envolvidas.

Como na terceira aplicação, notou-se que os(as) participantes 'sacrificavam' uma das vidas do jogo, a fim de não ser preciso realizar o desafio, o jogo foi novamente adaptado para que não fosse preciso jogar individualmente, mas coletivamente na quarta aplicação. Assim, o objetivo de todos(as) os(as) participantes era chegar ao centro do jogo juntos, ou seja, teriam que trabalhar e resolver os desafios em equipe. Desta vez, notou-se que as crianças respondiam aos desafios mais rápido e corretamente, além de que mostraram o raciocínio que cada uma tinha para resolver determinado problema. $\mathrm{Na}$ maioria das partidas tivemos equipes vencedoras e também o auxílio dos responsáveis que aprenderam juntamente com os(as) filhos(as). Vale ressaltar que a maioria das crianças não tinha nenhum conhecimento sobre computação e tiveram mais dificuldade no nível vermelho, o mais difícil dentre os níveis do jogo.

$\mathrm{Na}$ mais recente aplicação, isto é, na quinta aplicação, fez-se uma alteração no formato do tabuleiro, para atender uma maior quantidade de participantes durante o evento. Assim, jogou-se com quatro duplas em cada partida, ou seja, as duplas disputaram entre si. Essa versão do tabuleiro se tornou mais dinâmica, pois foi desenvolvida no chão, tornando-o mais atrativo. Dessa vez, as crianças não tiveram tanta dificuldade, tendo em vista que a maioria já havia aprendido alguns conceitos em 
VIII Congresso Brasileiro de Informática na Educação (CBIE 2019)

Anais do XXV Workshop de Informática na Escola (WIE 2019)

cursos de Pensamento Computacional, Desenvolvimento de Aplicativos para Celular, Desenvolvimento de Jogos, Modelagem 3D ou Robótica.

\section{Conclusões}

As aplicações do Loop - Tabuleiro lógico permitiram constatar que esse jogo pode ser utilizado como recurso pedagógico para o desenvolvimento de habilidades relacionadas ao pensamento computacional. $\mathrm{O}$ fato de a proposta ser interdisciplinar favorece a adesão de professores das áreas de matemática e de língua portuguesa em relação a esse recurso. Ademais, a proposta desplugada facilita a sua adoção em contextos educacionais em que não há amplo acesso às tecnologias digitais.

As aplicações permitiram o aprimoramento dos desafios no que se refere à transposição didática de alguns conteúdos. Constata-se ainda haver, em relação a isso, necessidade de aprimoramento das versões existentes.

Como projeção, pretende-se desenvolver versões diferentes do jogo, com níveis de dificuldade: básico, intermediário e avançado, levando em consideração também a possibilidade de fazer versões específicas para diferentes faixas etárias. Pretende-se também investir em uma versão para computador (plugada).

\section{Referências}

BELL, T.; WITTEN, I. e FELLOWS, M. (2011). "Computer Science Unplugged Ensinando Ciência da Computação sem o uso do Computador". Tradução de Luciano Porto Barreto, 2011. Disponível em: http://csunplugged.org/. Acesso em: maio/2019

SBC. (2018). Diretrizes para ensino de computação na educação básica. Disponível em:

https://www.sbc.org.br/documentos-da-sbc/category/131-curriculos-de-referencia. Acesso em: maio/2019.

VIEIRA, A. and Odette Passos, R. B. (2013). Um relato de experiência do uso da técnica computação desplugada. In: XXXIII Congresso da Sociedade Brasileira da Computação, p. 671-680. 